\title{
Quantitative Analysis on Heat Storage Capacity in Steam and Metal of Ultra-Supercritical Once-Through Boiler
}

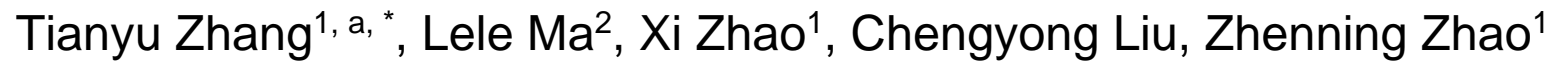 \\ ${ }^{1}$ North China Electric Power Research Institute, Beijing 100032, China. \\ ${ }^{2}$ North China Electric Power Research Institute (Xi'an) Co., Ltd, Xi'an 710065, China. \\ *, a zzztttyyy456@126.com
}

\begin{abstract}
As an increasing number of power plants are engaged in grid peaking operations, the utility boiler working condition varies frequently and violently, which demands a more flexible and accurate control system. In present investigation, a model measuring heat storage capacity in steam and metal with operating data of $1000 \mathrm{MW}$ unit is proposed. In the scope of investigation, calculated result shows the overall heat coefficient in subcritical working condition is $27 \%$ more than that in supercritical condition. The heat storage coefficient distribution of steam and metal varies with the change of working condition, and detailed information is exhibited. Moreover, reheat steam system is also in the scope of present investigation which is rarely reported.
\end{abstract}

Keywords: once-through boiler, ultra-supercritical and subcritical, heat storage coefficient.

\section{Introduction}

As an increasing number of power plants participate in grid peaking operation, it demands a more accurate control system to coordinate the fuel and feedwater supply in load changing process [1]. However, the sole change of fuel and feedwater supply may not fulfill the requirement of quick load change of unit. And the unit safe operation is also threatened by the changing quality of fuel, which can not be handled properly in current control system [2].

The energy stored in boiler draws many researchers' concern and investigation. Their investigation methods are mainly divided into experimental and analytical methods. Experimental methods are work-demanding and lack of accuracy [3] due to repeatability of experiment condition. Moreover, the experimental methods can rarely be applied because of the risk of unit safe operation or the limit of grid. Reprehensive simulation method and relevant terms can be referred in the study of [4].

However, current simulation method mentioned above 1) neglect the energy stored in reheat steam and reheater metal and 2) commonly takes advantage of design data instead of unit operating data, which may leads to deviation of calculated result.

\section{Model and Governing Equations}

The boiler studied in present paper is a super supercritical pressure once-through boiler produced by the Shanghai Boiler Works. This type is single furnace, double tangential combustion chamber, single reheat, balanced ventilation, semi open-air layout, solid slag discharge, all steel frame, full suspension structure coal pulverized coal boiler.

Table 1. Boiler Main Parameter

\begin{tabular}{cccc}
\hline Item & Unit & BMCR & BRL \\
\hline Main steam flow & $\mathrm{t} / \mathrm{h}$ & 3005 & 2918 \\
Main steam pressure & $\mathrm{MPa}(\mathrm{g})$ & 29.3 & 29.22 \\
Main steam temperature & ${ }^{\circ} \mathrm{C}$ & 605 & 605 \\
Reheat steam flow & $\mathrm{t} / \mathrm{h}$ & 2455 & 2370 \\
Reheat steam pressure & & & 5.74 \\
$\quad$ (outlet) & $\mathrm{MPa}(\mathrm{g})$ & 5.96 & 623 \\
Reheat steam pressure & ${ }^{\circ} \mathrm{C}$ & 623 & 302 \\
Feedwater temperature & ${ }^{\circ} \mathrm{C}$ & 305 & \\
\hline
\end{tabular}


Table 2. Typical Working Condition Parameters of Supercritical and Subcritical

\begin{tabular}{cccc}
\hline Item & unit & Supercritical & Subcritical \\
\hline Economizer inlet temperature & ${ }^{\circ} \mathrm{C}$ & 304.4 & 266 \\
Economizer outlet temperature & ${ }^{\circ} \mathrm{C}$ & 338.9 & 321.1 \\
Feedwater pressure & $\mathrm{MPa}(\mathrm{g})$ & 31.4 & 17.3 \\
Separator outlet temperature & ${ }^{\circ} \mathrm{C}$ & 431.9 & 412.3 \\
Separator outlet pressure & $\mathrm{MPa}(\mathrm{g})$ & 29.5 & 16.2 \\
final superheater & ${ }^{\circ} \mathrm{C}$ & $457.3 / 501.8 / 559.6 / 598.8$ & $441.3 / 489 / 559.5 / 601.3$ \\
Outlet temperature of primary, platen, rear and & & & $346.8 / 469.8$ \\
Inlet and outlet temperature of low temperature & ${ }^{\circ} \mathrm{C}$ & $353.4 / 512.1$ & 569.7 \\
reheater & ${ }^{\circ} \mathrm{C}$ & 603.6 & 2.96 \\
Reheat steam temperature & $\mathrm{MPa}(\mathrm{g})$ & 5.88 & \\
Reheat Steam pressure & & &
\end{tabular}

The definition of heat storage capacity is described as in literature [1]. The heat storage mainly consists of two parts: steam/water heat storage and metallic heat storage. When the steam pressure decreases, the steam/water begins to expand and pushes the steam in final superheater into turbine to do work. And this part of heat carried by steam is called steam/water heat storage. Meanwhile, the decrease in steam pressure will also result in decrease in heating surface temperature, and thus release the heat storage in metal. Therefore, the overall heat storage is the sum of steam/water heat storage and metallic heat storage [4].

According to the mass and energy conservation and steam/water characteristics, the steam/water heat storage can be divided into two parts: the heated media with phase change and without phase change, by which two different calculating methods are applied.

For media without phase change (e.g. subcooled water and superheated steam), when pressure goes down, the specific enthalpy keeps constant. According to mass and conservation:

$$
\begin{aligned}
& \frac{V_{0}}{v_{0}}=\frac{V_{1}}{v_{1}} \\
& h_{0}=h_{1}
\end{aligned}
$$

where $\quad V_{0}, V_{1} \quad$ - Volume before and after pressure changes, $\mathrm{m}^{3}$;

$$
\begin{array}{lll}
v_{0}, v_{1} & - & \text { Specific volume before and after pressure changes, } \mathrm{m}^{3} / \mathrm{kg} \\
h_{0}, h_{1} & - & \text { Specific enthalpy, } \mathrm{kJ} / \mathrm{kg} \text {. }
\end{array}
$$

Assume $V_{0}=1 \mathrm{~m}^{3}$ and the amplitude in pressure change is $1 \mathrm{MPa}$, then the media volume change after pressure changes is:

$$
\Delta \mathrm{V}_{i}=\mathrm{V}_{1}-\mathrm{V}_{0}
$$

where $\Delta \mathrm{V}_{i} \quad$ - $\quad$ Media volume change after pressure changes, $\mathrm{m}^{3} /\left(\mathrm{m}^{3} \cdot \mathrm{MPa}\right)$.

For media with phase change (e.g. saturate water and steam section of waterwall), when pressure goes down, part of saturate water evaporates into steam. According to mass and conversation, following equations can be given (subscript 1 and 0 means after and before pressure chagnes):

$$
\begin{aligned}
\frac{V_{s, 0}}{v_{s, 0}}+\frac{V_{w, 0}}{v_{w, 0}} & =\frac{V_{s, 1}}{v_{s, 1}}+\frac{V_{w, 1}}{v_{w, 1}} \\
\frac{V_{s, 0}}{v_{s, 0}} h_{s, 0}+\frac{V_{w, 0}}{v_{w, 0}} h_{w, 0} & =\frac{V_{s, 1}}{v_{s, 1}} h_{s, 1}+\frac{V_{w, 1}}{v_{w, 1}} h_{w, 1}
\end{aligned}
$$

where $\quad V_{s, 0}, V_{w, 0}-\quad$ Volume occupied by water and steam before pressure changes, $\mathrm{m}^{3}$;

$$
\begin{array}{cc}
v_{s, 0}, v_{w, 0}- & \text { Specific volume of water and steam before pressure changes, } \\
\mathrm{m}^{3} / \mathrm{kg} ; & \quad \text { Specific enthalpy of saturate water and steam before pressure } \\
h_{s, 0}, h_{w, 0} & -\begin{array}{c}
\text { changes, } \mathrm{kJ} / \mathrm{kg} ;
\end{array}
\end{array}
$$


In present paper, it is assumed that volume occupied by water and steam before pressure changes is equal, namely $V_{s, 0}=V_{w, 0}$, and the amplitude of pressure change is $1 \mathrm{MPa}$. Therefore, based on steam/water characteristic, $V_{s, 1}$ and $V_{w, 1}$ can be obtained. And the volume change after pressure changes is:

$$
\Delta \mathrm{V}_{p, i}=V_{s, 1}+V_{w, 1}-V_{s, 0}-V_{w, 0}
$$

where $\Delta \mathrm{V}_{p, i} \quad$ - $\quad$ Media volume change after pressure changes, $\mathrm{m}^{3} / \mathrm{m}^{3} \cdot \mathrm{MPa}$ ).

Hence, the heat storage coefficient in main steam system and reheat steam system are:

$$
\begin{aligned}
H m_{i} & =\frac{h_{m}}{v_{m}} \times \Delta \mathrm{V}_{i} \\
H r_{j} & =\frac{h_{r}}{v_{r}} \times \Delta \mathrm{V}_{j}
\end{aligned}
$$

where $H m_{i} \quad$ Heat storage coefficient of ith part in main steam system, $\mathrm{kJ} /\left(\mathrm{MPa} \cdot \mathrm{m}^{3}\right)$;

$H_{j} \quad$ - Heat storage coefficient of jth part in reheat steam system, $\mathrm{kJ} /\left(\mathrm{MPa} \cdot \mathrm{m}^{3}\right)$;

The overall steam/water heat can be calculated as:

$$
H_{\text {steam }}=\sum_{i=1}^{n} H m_{i} \times \mathrm{V}_{i}+\sum_{j=1}^{m} H r_{j} \times \mathrm{V}_{j}
$$

where $\quad H s \quad$ - $\quad$ Overall heat storage coefficient of steam/water, $\mathrm{kJ} /\left(\mathrm{MPa} \cdot \mathrm{m}^{3}\right)$;

For metallic heat storage, it is assumed that the value of metal temperature variation is as same as the average media temperature change. Therefore, the individual and overall metallic heat storage coefficients are:

$$
\begin{aligned}
& H m e_{i}=c_{p} m_{i} \times \Delta \mathrm{t}_{i} \\
& H_{\text {metal }}=\sum_{i=1}^{o} H m e_{i}
\end{aligned}
$$

where $\mathrm{Hme}_{i} \quad$ Individual heat storage coefficient of heating surfaces i, $\mathrm{kJ} /\left(\mathrm{MPa} \cdot \mathrm{m}^{3}\right)$;

$H_{\text {metal }} \quad$ Overall heat storage coefficient of heating surfaces, $\mathrm{kJ} /\left(\mathrm{MPa} \cdot \mathrm{m}^{3}\right)$;

Mass and volume of heating surfaces for calculation are listed in Table 3.

Table 3. Mass and Volume of Heating Surfaces

\begin{tabular}{c|c|c}
\hline Heating Surface & Mass $/ 10^{3} \times \mathrm{kg}$ & Volume $/ \mathrm{m}^{3}$ \\
\hline Economizer & 3630 & 150 \\
\hline Waterwall & 1434 & 122 \\
\hline Primary Superheater & 1427 & 151 \\
\hline Platen Superheater & 215 & 22 \\
\hline Rear Superheater & 210 & 22 \\
\hline Final Superheater & 268 & 28 \\
\hline Low-temperature reheater & 1361 & 465 \\
\hline High-temperature reheater & 472 & 155 \\
\hline
\end{tabular}

\section{Results and Thermal Analysis}

\subsection{Heat Storage in Steam}

In this section, two typical working condition of supercritical and subcritical, respectively, are studied. And heat storage in steam/water system and metal are analyzed. 


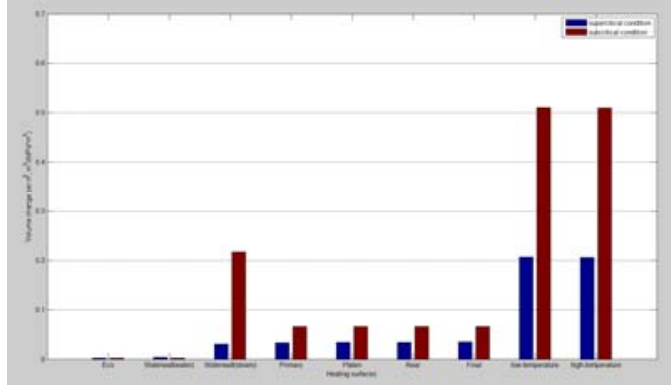

(a)Volume Change Per Unit Volume

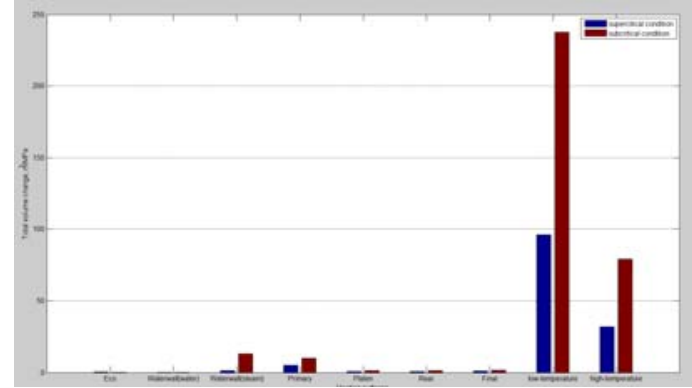

(b) Overall Volume Change

Fig 1. Volume Change as Pressure Changes $1 \mathrm{MPa}$

The heating surfaces are listed along x-axis in Figure 1, among which waterwall is divided into water and steam part. Water part consists of preheating water period, which is separated according to media enthalpy distribution in waterwall. Main volume change occurs in waterwall steam part and reheater, it is mainly because 1 ) in waterwall steam part, as pressure decreases, part of saturate water begins to evaporate and saturate steam begins to expand, 2) in reheater, the steam pressure is much lower than that of main stream, and the specific volume changes more violently when pressure change occurs at low pressure, which leads to great change of volume.

As shown in Figure. 1(b), the volume change of reheater is dominant compared with volume changes in other heating surfaces due to its vast original volume as listed in Table. 3. According to Formula 7, 8, the heat storage in steam can be calculated as shown in Figure. 2.

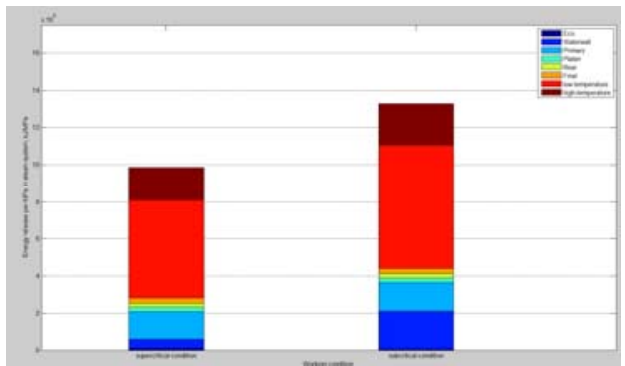

Fig.2 Heat Storage Distribution in Steam

As shown in Figure. 2, a large part of heat storage lies in reheater and a small amount lies in primary overheater and waterwall in terms of steam heat storage. Meanwhile, heat storage of other heating surfaces is such minimal that can be neglected in actual working condition. Specific volume change determines the volume change per $\mathrm{MPa}$, and the original volume is designed according to thermal calculation by manufacturer. The former is determined by steam and water thermo-physical characteristic (thus influenced by different working condition), and the latter is structure data which can be rarely changed.

It can be also seen that the working condition of subcritical is $28 \%$ more than that of supercritical condition, which indicates when load changes, subcritical working condition is more prone to keep a constant pressure in terms of heat storage in steam.

\subsection{Heat Storage in Metal}

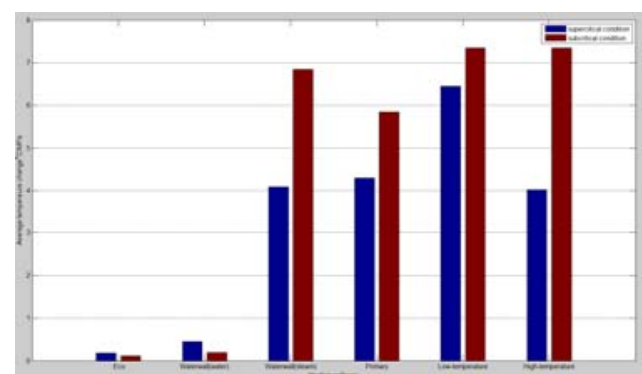

Fig.3 Average Temperature Change

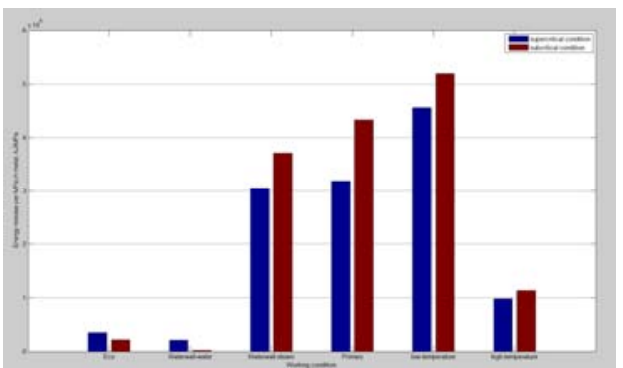

Fig.4 Overall Heat Storage in Metal 
Due to the existence of desuperheating water and relatively steady steam/metal temperature, the platen, rear and final overheaters are not accounted in terms of heat storage in metal. From Fig 3, it can be seen that the temperature change in supercritical is less than that in subcritical working condition except for waterwall water part, though its amount is minimal. Heat storage in metal, as heat storage in steam, is great influenced by heating surfaces mass as shown in Fig. 4.

\subsection{Overall Heat Storage}

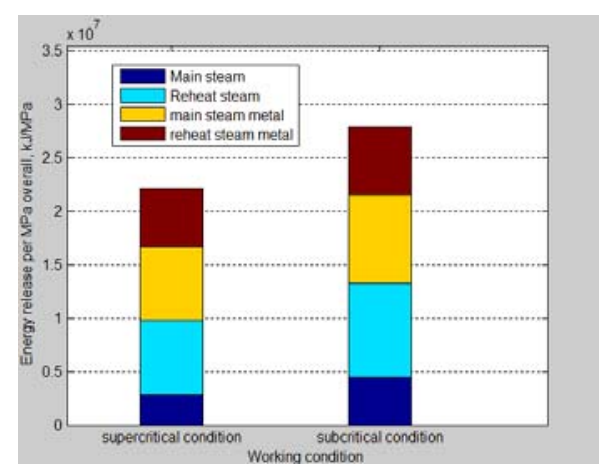

Figure 5. Overall Heat Storage

Fig 5 shows the heat storage distribution in water\&steam and metal of main and reheat system, respectively. It can be figured out that heat storage in subcritical condition reaches about $2.8 \times$ $10^{7} \mathrm{~kJ} / \mathrm{MPa}$, exceeding that in supercritical condition $\left(2.2 \times 10^{7} \mathrm{~kJ} / \mathrm{MPa}\right)$ by $27 \%$, which means as pressure decreases, the heat storage increases to slow down the pressure varying rate. And the metal heat storage accounts for of $56 \%$ and $52 \%$ of overall heat storage in supercritical and subcritical working condition, respectively. The heat storage in reheater system (steam\&water and metal included) accounts for 56\% and 54\% of overall heat storage in two working conditions, and this part of heat storage is commonly ignored in previous literature.

\section{Conclusion}

Through experimental data and thermal analysis, following conclusions can be made.

(1) In the working condition investigated in present study, the heat storage of subcritical working condition is $2.8 \times 10^{7} \mathrm{~kJ} / \mathrm{MPa}$, exceeding that of supercritical working condition $\left(2.2 \times 10^{7} \mathrm{~kJ} / \mathrm{MPa}\right)$ by $27 \%$.

(2) Heat storage in metal makes up a share of 56\% and 52\% in supercritical and subcritical working condition, respectively, which indicates heat storage in low-load mainly lies in steam and water system.

(3) Reheat system heat storage accounts for $56 \%$ and $54 \%$ of overall heat storage, which cannot be neglected during dynamic analysis.

(4) In steam heat storage, the share in waterwall steam part), primary overheater, and reheater is dominant. And it shows the similar regulations in metal heat storage.

These conclusions mentioned above can be used as reference for actual operations. And detailed investigation in heat storage distribution in dynamic change will be carried on in further study.

\section{References}

[1]. T Deng, T Liang, et al. Quantitative Analysis on Heat Storage Capacity of Ultra-supercritical Once-through Boilers[J]. Journal of Chinese Society of Power Engineering, 2012,Vol.32.

[2]. X Liu, L Tian, et al. The quantitative analysis of the drum boiler heat storage coefficient [J] .Journal of Power Engineering, 2008, 28(2):216-220. 
[3]. J Gu, et al. The calculation of supercrtitical boiler heat storage coefficient [J]. Boiler Technology, 2012,43(3):1-4.

[4]. J Shu. The theoretical calculation of boiler regenerative coefficient [J]. Jiangsu Eletrical Engineering. 2003.22(6):31-33. 